\title{
Intensive care unit professionals during the COVID-19 pandemic in Spain: social and work-related variables, COVID-19 symptoms, worries, and generalized anxiety levels
}

\author{
Fernando J. García-Hedrera', Fernanda Gil-Almagro', F. Javier Carmona-Monge², Cecilia Peñacoba-Puente ${ }^{3}$, \\ Patricia Catalá-Mesón ${ }^{3}$, Lilian Velasco-Furlong ${ }^{3}$
}

'Unidad de Cuidados Críticos, Hospital Universitario Fundación Alcorcón, Madrid; ${ }^{2}$ Servicio de Anestesiología, Complejo Hospitalario Universitario de Santiago de Compostela, Santiago de Compostela; ${ }^{3}$ Departamento de Psicología, Universidad Rey Juan Carlos, Alcorcón, Spain

Background: The severe acute respiratory syndrome coronavirus 2 outbreak has been identified as a pandemic and global health emergency. It presents as a severe acute respiratory disease. The rapid dissemination of the disease created challenges for healthcare systems and forced healthcare workers ( $\mathrm{HCWs)} \mathrm{to} \mathrm{deal} \mathrm{with} \mathrm{many} \mathrm{clinical} \mathrm{and} \mathrm{nonclinical} \mathrm{stresses.} \mathrm{The} \mathrm{aim}$ of our research is to describe work conditions, symptoms experienced by HCWs, worries about contagion, and generalized anxiety symptoms and compare those findings across regions in Spain.

Methods: This cross-sectional study was conducted using an online survey. Critical care units throughout Spain were included. The sample comprised HCWs working in intensive care units from March to May 2020. We assessed work variables, physical symptoms, worries about contagion, and anxiety (generalized anxiety disorder-7 questionnaire).

Results: The final sample comprised 448 surveys. Among the respondents, 86.9\% $(n=389)$ were nursing professionals, and $84.8 \%(n=380)$ were women. All participants cared for coronavirus disease 2019 (COVID-19) patients during the study period. Workload during the pandemic in Madrid was judged to be higher than in other regions $(P<0.01)$. The availability of personal protective equipment was found to be higher in Cataluña. The most frequently experienced symptom was headaches $(78.1 \%)$. Worries about self-infection and the possibility of infecting others received mean scores of 3.11 and 3.75, respectively. Mean scores for generalized anxiety levels were 11.02 , with $58.7 \%$ of the professionals presenting with generalized anxiety syndrome during the assessment.

Conclusions: In this study, we found high levels of anxiety among HCWs caring directly for COVID-19 patients, which could produce long-term psychological alterations that still need to be assessed.

Key Words: anxiety; COVID-19; health personnel; intensive care units; personal protective equipment; psychological stress; SARS-CoV-2

\section{INTRODUCTION}

On December 31, 2019, the municipal health commission of the city of Wuhan (Hubei Province, China) reported the existence of 27 cases of pneumonia of unknown etiology. The onset

\section{Original Article}

Received: February 17, 2021

Revised: April 12, 2021

Accepted: May 1, 2021

Corresponding author

Fernanda Gil-Almagro

Unidad de Cuidados Críticos,

Hospital Universitario Fundación

Alcorcón, c/ Budapest 1, 28922

Alcorcón (Madrid), Spain

Tel: +34-6-2645-9149

Fax: +34-9-1621-9750

E-mail: fgilalmagro@gmail.com

Copyright (c) 2021 The Korean Society of Critical Care Medicine

This is an Open Access article distributed under the terms of Creative Attributions Non-Commercial License (https://

creativecommons.org/li-censes/by-nc/4.0/) which permits unrestricted noncommercial use, distribution, and reproduction in any medium, provided the original work is properly cited. 
of symptoms had occurred on December 8, and seven of the cases were severe. At that point, the source of the outbreak was undisclosed. On January 7, 2020, Chinese authorities identified the causal agent as a new RNA virus of the Coronaviridae family, and the condition was therefore named severe acute respiratory syndrome coronavirus 2 (SARS-Cov-2). Since that time, we have learned that transmission occurs through respiration, i.e., the virus is held in droplets of exhaled air that then have direct contact with the conjunctiva and nasal and oral mucosa of nearby people [1,2]. On March 11, 2020, the World Health Organization labeled the situation a global pandemic [3]. In the weeks immediately after that declaration, two countries with a particularly high incidence of cases and mortality were Spain and Italy $[4,5]$. In both countries, specific regions experienced overwhelming demand on the health care system, far surpassing the capacity of hospitals to attend to all the patients needing medical care [6]. In Spain, furthermore, the health system has decentralized, economic management, so the competence of the human and material resources is the responsibility of each region. Despite the important benefits offered by this type of organization in most situations, it can produce regional differences in management during an emergency situation such as a global pandemic, and those managerial differences can produce different health results [7].

As of July 24, 2020, Spain has reported a total of 272,241 confirmed cases. Of those patients, 126,315 (46.4\%) have been hospitalized, and 11,743 have been admitted to an intensive care unit (ICU) (4.3\%). Spain has had one of the highest incidences of coronavirus disease 2019 (COVID-19) in the world $[6,8]$. Nationwide, all regions have been affected by COVID-19 to some extent, and the national health system and its workers have been subjected to a heavier burden than ever before. However, some regions have been more severely affected by COVID-19 than others. Madrid (73,944 cases) and Cataluña (72,919 cases) have had more cases, hospital admissions, and ICU admissions than other regions, at least in part because they contain the two largest cities in Spain: Madrid, the capital of Spain, has a population of 3,334,730 plus a large population in the city's suburbs, and Barcelona, which has a population of 1,664,182 without counting its suburbs. Their high population density and the agglomerations of people using public transport and those cities' large leisure and shopping areas facilitated early contagion between individuals and allowed the virus to spread rapidly.

The most acute phase of the pandemic placed a huge strain on healthcare workers (HCWs), which greatly affected both their physical and emotional well-being. Hospital systems ran

\section{KEY MESSAGES}

- Organizational issues and perceived risks seem to affect healthcare worker (HCW) mental health.

- Worry about self-infection was an important source of stress for HCW during the first wave of the pandemic.

- Regions in Spain differed widely in the availability of personal protective equipment and perceived workload from March to May 2020, which needs to be addressed to ensure that all regions have equal resources in future crisis situations.

well above their full capacity, and serious shortages of critical care resources such as ventilators and personal protective equipment (PPE) occurred [9]. The lack of appropriate PPE, including gloves, face shields, gowns, and hand sanitizer, was a particular source of anxiety and stress among frontline HCWs. The lack of essential PPE might also have fed the high rates of infection among professionals seen in both Italy and Spain (although PPE availability was not distributed equally) $[10,11]$. Thus, resource shortages could have had a role in the development of anxiety, physical fatigue, or difficulties in work performance. A report from China suggests that COVID-19 HCWs are experiencing elevated rates of mental health problems [12].

Different studies have identified fear of contagion (for oneself, children, or family) as another source of stress among the HCWs dealing with this pandemic. That fear can be exacerbated by a reduced availability of PPE, shortages of medical resources in the ICU, and working at full ICU capacity, and it has also been identified as a source of issues such as insomnia, irritability, and decreased appetite [12-15].

Our aim in this study was to describe and compare different regions in Spain (Madrid, Cataluña, and the remaining regions [RRs]) in terms of the work conditions for frontline HCWs that could have acted as stressors during the pandemic. Furthermore, we aimed to describe COVD-19 symptoms experienced by HCWs during the pandemic and compare them among regions. Finally, we analyzed HCWs' worries about contagion and generalized anxiety symptoms and compared them among regions.

\section{MATERIALS AND METHODS}

\section{Design}

This cross-sectional study collected data using an online electronic form designed for this purpose by the research team. Data were collected during May and June 2020 from HCWs 
who worked in ICUs from March to May 2020.

\section{Study Variables}

We began by reviewing previous surveys used to assess the conditions of HCWs during this pandemic and previous outbreaks of infectious diseases (SARS, Middle East respiratory syndrome [MERS], and H1N1) [16-19]. Then we collected information regarding the work situation of ICU professionals and the physical symptoms they experienced during the time they were caring for COVID-19 patients, as reported by Stokes et al. [20] (fever, chills, headache, cough, myalgias, shortness of breath, dizziness, rhinitis, sore throat, chest pain, anosmia, ageusia, and skin manifestations).

To assess the level of concern HCWs felt regarding infection, we used two items designed for that purpose that are similar to those used by Wang et al. [19] in their research: what is your level of concern about the possibility that you will contract COVID-19? and what is your level of concern that you could cause a member of your family to contract COVID-19? Those questions were answered using a Likert-type scale that ranged from 1 (not worried at all) to 4 (very worried).

Anxiety was assessed using the Spanish version of the generalized anxiety disorder (GAD)-7 questionnaire, which is a one-dimensional, self-administered scale designed to test for the presence of the GAD symptoms listed in the Diagnostic and Statistical Manual of Mental Disorders (DSM)-IV [21,22]. The total GAD-7 score is calculated by adding the answers for each item. Scores for all seven items range from 0 (not at all) to 3 (nearly every day). Therefore, the total score ranges from 0 to 21. The cut-off point for a diagnosis of GAD is a score equal to or greater than 10 [21]. The reliability of the scale in our sample was high, with a Cronbach's alpha value of 0.92 .

\section{Sample Election and Data Collection}

Data were collected using an online survey designed by the research team. The first page contained a description of the study's main objective. Sample selection was performed using a convenience, non-probabilistic snowball approach. First, we contacted critical care colleagues and sent them the survey link, asking them to help us reach other professionals working in their units or any other HCWs who might be interested in completing the survey. We also used social media networks (Facebook, Twitter, LinkedIn) to send the survey link to professional societies, health institutions, and Spanish professionals working in the Spanish health care system during the COVID-19 pandemic. The sample comprised registered nursing professionals and attending physicians working in critical care units and post-surgical critical care units from March to June 2020. All the participants cared for COVID-19 patients during that period. For the analyses, the sample was sorted into three groups by their location: Madrid, Cataluña, and the RR.

This study was approved by the Ethics Committee of the Hospital Universitario Fundación Alcorcón (20/88), and all participants provided informed consent to use all the data they provided before they completed the questionnaire.

\section{Statistical Analysis}

Analyses were performed using the IBM SPSS ver. 24 (IBM SPSS Corp., Armonk, NY, USA). Descriptive analyses and internal consistency analyses (Cronbach's alpha coefficients) were performed. The regional comparisons of the study variables (Madrid, Cataluña, and RR) used a one-way analysis of variance for quantitative variables with post-hoc Scheffé testing. For the qualitative variables, chi squares tests were performed. Differences were considered significant at $\mathrm{P}<0.05$.

\section{RESULTS}

\section{Sample Characteristics}

The final sample comprised 448 surveys completed by personnel working in ICUs or post-surgical critical care units throughout Spain. Within the total sample, $86.9 \%(n=389)$ of respondents were nursing professionals, and $84.8 \%(n=380)$ were women. Furthermore, $61.2 \%(n=274)$ were married or living with a partner, and $32.1 \%(n=144)$ were single. About forty percent $(39.3 \%, \mathrm{n}=176)$ had children living at home. The mean age of the respondents was 39.69 (standard deviation [SD], 10.55) in a range from 18 to 64 years. Most of the study population, 93.5\% $(n=419)$, lived at home during the pandemic, but $6.5 \%(n=29)$ lived at a hotel or home different from their usual one.

\section{Work Variables}

Table 1 shows descriptive statistics about work-related variables for the total sample, along with differences among regions. For the regional analyses, the sample was grouped by their location: Madrid ( $n=238,53.1 \%)$, Cataluña $(n=87,19.4 \%)$, and RR $(n=123,27.5 \%)$. Despite our efforts to provide a full picture of the situation for critical care professionals in Spain, responses were not homogeneous throughout the country, with some regions returning fewer than five responses (i.e., Galicia, Extremadura, and La Rioja) and some returning no responses, leaving them unrepresented in this research (i.e., Melilla). 
Table 1. Sociodemographic characteristics of the sample

\begin{tabular}{|c|c|c|c|c|c|c|}
\hline Variable & $\begin{array}{c}\text { Total sample } \\
(n=448)\end{array}$ & $\begin{array}{c}\text { Madrid (1) } \\
(n=238,53.1 \%)\end{array}$ & $\begin{array}{c}\text { Cataluña (2) } \\
(n=87,19.4 \%)\end{array}$ & $\begin{array}{c}\operatorname{RR}(3) \\
(n=123,27.5 \%) \\
\end{array}$ & $\mathrm{F} / \chi^{2}$ & P-value \\
\hline Experience in the unit (yr) & $9.78 \pm 9.21$ & $8.82 \pm 8.46$ & $9.44 \pm 9.32$ & $11.89 \pm 10.21$ & $F=4.675$ & $0.010^{\mathrm{a}}$ \\
\hline Work status & & & & & $\chi^{2}=5.203$ & 0.267 \\
\hline Permanent & $222(49.6)$ & $107(45)$ & $51(58.6)$ & $64(52)$ & & \\
\hline Intern & $94(21)$ & $55(23.1)$ & $15(17.2)$ & $24(19.5)$ & & \\
\hline Temporary & $132(29.5)$ & 76 (31.9) & $21(24.1)$ & $35(28.5)$ & & \\
\hline Shift & & & & & $\chi^{2}=73.914$ & $<0.001$ \\
\hline Fixed shift & $61(13.6)$ & $19(8)$ & $34(39.1)$ & $8(6.5)$ & & \\
\hline Shift rotation & $169(37.7)$ & $100(42)$ & $13(14.9)$ & $56(45.5)$ & & \\
\hline Shifts+on call & $45(10)$ & $29(12.2)$ & $2(2.3)$ & $14(11.4)$ & & \\
\hline $12 / 24$ hours & $173(38.6)$ & $90(37.8)$ & $38(43.7)$ & $45(36.6)$ & & \\
\hline Weekly hours & $45.01 \pm 10.9$ & $45.90 \pm 11.1$ & $45.66 \pm 10.4$ & $42.87 \pm 10.6$ & $F=3.361$ & $0.036^{b}$ \\
\hline Transferred to the ICU (yes) & $151(33.7)$ & $84(35.3)$ & $35(40.2)$ & $32(26)$ & $F=5.181$ & 0.075 \\
\hline Specifically hired for ICU during pandemic (yes) & $65(14.5)$ & $34(14.3)$ & $14(16.1)$ & $17(13.8)$ & $F=0.232$ & 0.890 \\
\hline Increase in the number of beds (yes) & $411(91.7)$ & $230(96.6)$ & $73(83.9)$ & $108(87.8)$ & $F=17.095$ & $<0.001$ \\
\hline Number of COVID patients & & & & & $\chi^{2}=23.765$ & 0.001 \\
\hline$<5$ & $8(1.8)$ & $3(1.3)$ & $1(1.1)$ & $4(3.3)$ & & \\
\hline $5-10$ & $38(8.5)$ & $7(2.9)$ & $12(13.8)$ & $19(15.4)$ & & \\
\hline $11-20$ & $137(30.6)$ & $75(31.5)$ & $29(33.3)$ & $33(26.8)$ & & \\
\hline$>20$ & $265(59.2)$ & $153(64.3)$ & $45(51.7)$ & $67(54.5)$ & & \\
\hline Patient/professional ratio during the pandemic & & & & & $\chi^{2}=35.867$ & $<0.001$ \\
\hline Lower than usual & $79(17.6)$ & $30(12.6)$ & $11(12.6)$ & $38(30.9)$ & & \\
\hline Same as usual & $181(40.4)$ & $90(37.8)$ & $52(59.8)$ & $39(31.7)$ & & \\
\hline Higher than usual & $88(42)$ & $118(49.6)$ & $24(27.6)$ & $46(37.4)$ & & \\
\hline Workload during the pandemic & & & & & $\chi^{2}=12.215$ & 0.016 \\
\hline Lower than usual & $4(0.9)$ & 0 & $1(1.1)$ & $3(2.4)$ & & \\
\hline Same as usual & $19(4.2)$ & $6(2.5)$ & $3(3.4)$ & $10(8.1)$ & & \\
\hline Higher than usual & 425 (94.9) & $232(97.5)$ & 83 (95.4) & $110(89.4)$ & & \\
\hline PPE availability & & & & & $\chi^{2}=31.021$ & $<0.001$ \\
\hline No, never & $13(2.9)$ & $9(3.8)$ & 0 & $4(3.3)$ & & \\
\hline Not enough & $199(44.4)$ & $119(50)$ & $26(29.9)$ & $54(43.9)$ & & \\
\hline Most of the time & $182(40.6)$ & $92(38.7)$ & $51(58.6)$ & $39(31.7)$ & & \\
\hline Yes, always & $54(12.1)$ & $18(7.6)$ & $10(11.5)$ & $26(21.1)$ & & \\
\hline
\end{tabular}

Values are presented as mean \pm standard deviation or number (\%).

RR: remaining region; ICU: intensive care unit; COVID: coronavirus disease; PPE: personal protective equipment.

aScheffé post-hoc (1-3), $\mathrm{P}=0.001$; 'bcheffé post-hoc (1-3), $\mathrm{P}=0.043$.

Generally speaking, the HCWs working during the pandemic had 10 years of work experience; half of them worked on permanent contracts, and they worked rotating or 12/24-hour shifts. Our respondents worked 45 hours per week on average. One third of them were transferred to the ICU during the pandemic, and $14.5 \%$ of them were hired specifically for ICU work during this period. Overload indicators were widespread during this period. More than $90 \%$ of our respondents reported that their hospitals expanded the number of beds, about $60 \%$ treated more than 20 COVID patients, and $95 \%$ reported that their workloads were higher than usual. Almost half (45\%) of our sample did not always have adequate PPE. 
Differences between Madrid, Cataluña, and the RR

Significant differences were found among all groups regarding work experience in ICU (years) $(\mathrm{P}=0.010)$. Significant post-hoc differences were found $(\mathrm{P}=0.011)$ between Madrid (with the lowest scores; mean, 8.82) and the RR (with the highest scores; mean, 11.89).

Statistically significant differences were also observed in the types of shifts worked $(\mathrm{P}<0.001)$. Madrid and the RR showed high rates of rotating shifts ( $42 \%$ and $45.5 \%$, respectively), whereas HCWs in Cataluña reported a high percentage of fixed shifts (39.1\%). The 12/24 hour shift was found in similar percentages in all three locations, around $40 \%$. Weekly hours worked also differed significantly between Madrid, with the highest scores (mean, 45.90), and the RR (mean, 42.87) ( $\mathrm{P}=0.036)$.

Statistically significant differences were observed between Madrid (96.6\%) and Cataluña (83.9\%) in hospitals that increased the number of beds $(\mathrm{P}<0.001)$. The number of COVID patients per unit also differed significantly $(\mathrm{P}=0.001)$ between Madrid, which had the highest percentages of patients in ICU, and the rest of the regions (95.8\% vs. $81.3 \%$ had more than 11 patients). The patient/professional ratio during the pandemic differed significantly between regions $(\mathrm{P}<0.001)$ as well. In Madrid, $49.6 \%$ of professionals rated it as higher than usual, compared with $27.6 \%$ in Cataluña. Regarding the workload during the pandemic $(\mathrm{P}=0.016), 97.5 \%$ of professionals in Madrid judged it as higher than usual, compared with $89.4 \%$ in the other regions. Finally, regarding the availability of PPE
$(\mathrm{P}<0.001)$, the least satisfied professionals were in Madrid and RR, where $53.8 \%$ and $47.2 \%$ of respondents, respectively, reported that it was not always available. HCWs in Cataluña reported the highest availability of PPE, with only $29.9 \%$ saying it was not always available.

\section{COVID-19 Symptoms}

Table 2 shows descriptive statistics about COVID-19 symptoms for the total sample, along with differences among regions. The most frequently experienced symptom was headaches (78.1\%). Sore throats were present in fewer than half of the participants (42.2\%). The least experienced symptoms were anosmia and ageusia ( $8.9 \%$ and $9.2 \%$ respectively). All the percentages were similar among professionals from different regions. The only statistically significant differences observed were in myalgias $(\mathrm{P}=0.020)$, with professionals from Madrid (42.1\%) reporting them most often.

\section{Worries about Infection and Anxiety}

Table 3 shows HCWs' worries about self-infection (3.11) and about the possibility of infecting others (3.75) (range, 1-4). The generalized anxiety scores were 11.02 (SD, 5.57; range, 0-21). Given the cut-off point established for diagnosis (scores equal to or greater than 10), $58.7 \%$ of our HCW respondents presented with GAD at the moment of assessment. No statistically significant differences between regions were found for these indicators.

Table 2. Clinical manifestations of COVID-19

\begin{tabular}{|c|c|c|c|c|c|c|}
\hline Symptom & $\begin{array}{l}\text { Total sample } \\
\quad(n=448)\end{array}$ & $\begin{array}{c}\text { Madrid } \\
(n=238,53.1 \%)\end{array}$ & $\begin{array}{c}\text { Cataluña } \\
(n=87,19.4 \%)\end{array}$ & $\begin{array}{c}R R \\
(n=123,27.5 \%)\end{array}$ & $\mathrm{F}$ & P-value \\
\hline Fever & $55(17.5)$ & 39 (19.3) & $8(12.3)$ & $8(16.7)$ & 1.696 & 0.428 \\
\hline Chills & 69 (21.9) & $46(22.8)$ & $11(16.9)$ & $12(25)$ & 1.301 & 0.522 \\
\hline Headache & $246(78.1)$ & $165(81.7)$ & $46(70.8)$ & 35 (72.9) & 4.312 & 0.116 \\
\hline Cough & $117(37.1)$ & $83(41.1)$ & 21 (32.3) & $13(27.1)$ & 4.079 & 0.130 \\
\hline Myalgia & $115(36.5)$ & $85(42.1)$ & $16(24.6)$ & $14(29.2)$ & 7.787 & 0.020 \\
\hline Shortness of breath & $41(13)$ & $31(15.3)$ & $3(4.6)$ & $7(14.6)$ & 5.125 & 0.077 \\
\hline Dizziness & 69 (21.9) & $49(24.3)$ & $11(16.9)$ & $9(18.8)$ & 1.876 & 0.391 \\
\hline Rhinitis & $71(22.5)$ & 47 (23.3) & $17(26.2)$ & 7 (14.6) & 2.288 & 0.319 \\
\hline Sore throat & $133(42.2)$ & $85(42.1)$ & $29(44.6)$ & 19 (39.6) & 0.291 & 0.864 \\
\hline Chest pain & $63(20)$ & $45(22.3)$ & $11(16.9)$ & $7(14.6)$ & 1.920 & 0.383 \\
\hline Anosmia & $28(8.9)$ & $19(9.4)$ & $7(10.8)$ & $2(4.2)$ & 1.672 & 0.433 \\
\hline Ageusia & $29(9.2)$ & $21(10.4)$ & $6(9.2)$ & $2(4.2)$ & 1.801 & 0.406 \\
\hline Skin manifestations & $46(14.6)$ & $30(14.9)$ & $9(13.8)$ & $7(14.6)$ & 0.040 & 0.980 \\
\hline
\end{tabular}

Values are presented as number (\%).

COVID-19: coronavirus disease 2019; RR: remaining region. 
Table 3. Worry about contagion and generalized anxiety disorder

\begin{tabular}{lcccccc}
\hline Variable & $\begin{array}{c}\text { Total sample } \\
(\mathrm{n}=448)\end{array}$ & $\begin{array}{c}\text { Madrid } \\
(\mathrm{n}=238,53.1 \%)\end{array}$ & $\begin{array}{c}\text { Cataluña } \\
(\mathrm{n}=87,19.4 \%)\end{array}$ & $\begin{array}{c}\mathrm{RR} \\
(\mathrm{n}=123,27.5 \%)\end{array}$ & $\mathrm{F} / \chi^{2}$ & $\mathrm{P}$-value \\
\hline Worried about own contagion & $3.11 \pm 0.79$ & $3.12 \pm 0.80$ & $3.11 \pm 0.75$ & $3.04 \pm 0.78$ & $\mathrm{~F}=0.208$ & 0.592 \\
Worried about family contagion & $3.75 \pm 0.57$ & $3.73 \pm 0.61$ & $3.82 \pm 0.46$ & $3.75 \pm 0.52$ & $\mathrm{~F}=0.513$ & 0.599 \\
Generalized anxiety disorder & $11.02 \pm 5.57$ & $11.20 \pm 5.71$ & $10.98 \pm 0.64$ & $10.29 \pm 5.50$ & $\mathrm{~F}=0.524$ & 0.592 \\
GAD-7 $\geq 10$ & $263(58.7)$ & $145(60.9)$ & $48(55.2)$ & $70(56.9)$ & $\chi^{2}=1.095$ & 0.578 \\
\hline
\end{tabular}

Values are presented as mean \pm standard deviation or number (\%).

RR: remaining region; GAD: generalized anxiety disorder.

\section{DISCUSSION}

In this study, we have described the work conditions, physical symptoms resembling COVID-19, and generalized anxiety symptoms of HCWs working in ICUs and compared those results across different regions of Spain. The findings of this study indicate that ICU personnel experienced high levels of anxiety (about $60 \%$ of the population had scores meeting a GAD diagnosis) throughout Spanish territory. Regional differences were found in important working conditions, such as the amount of experience professionals had in the ICU, patient to professional ratio during the pandemic, and PPE availability during the study period.

Several studies have highlighted the significant mental-health consequences that this pandemic has had for the HCWs working on its front lines. However, no previous studies have focused on critical care workers. Furthermore, to the best of our knowledge, this is the first study to assess Spanish ICU workers at a moment when the critical situation created by the pandemic was still occurring. Several studies assessed anxiety among COVID-19 workers in China, and they used different tools for their assessments [23]. The estimated prevalence of anxiety in those studies was $23.1 \%$, which is significantly lower than the result we obtained in this study. We found that in the three months following the onset of the pandemic, up to $60 \%$ of the HCWs assessed met the criteria for a GAD diagnosis according to the answers they provided to the GAD-7 questionnaire [12,24-26]. The data about anxiety obtained in China were very similar for both HCWs and the general population. In Italy, Rossi et al. [27] found results similar to the Chinese studies regarding the prevalence of anxiety in HCWs (19.80\%). In New York state, nurses were more likely than attending physicians and house staff to screen positive for anxiety ( $40 \%$ vs. $15 \%$ and $17 \%$, respectively) [28]. In Spain, González-Sanguino et al. [29] used the GAD-2 questionnaire to test the general population and found a prevalence of anxiety that was much lower than what we found in our sample of HCWs (21.6\% vs.
$58.7 \%)$. The variability of those results could reflect the different instruments used and the different moments of measurement. In this context, it should be remembered that we were surveying ICU HCWs in Spain during the most critical months of the pandemic. The higher prevalence of anxiety in our sample could also reflect the fact that the response rate to our survey was highest among professionals working in the regions of Spain most heavily affected by COVID-19, which also saw a higher rate of hospital and ICU admissions than other areas. Although the results presented here are not in accordance with those of previous studies, the high prevalence in anxiety in this sample highlights the devastating effects that the COVID-19 pandemic has had on the psychological health of HCWs [30]. These results show the uncontestable need for a change in health care institutions. A team dedicated to training HCWs in the management of their emotions would be an interesting addition to these environments. Such training would give professionals facing a new pandemic training in emotional control and equip them with the tools and skills they need to face work alterations and thus prevent the development of psychological disorders [31]. In fact, some healthcare systems and professional organizations have already pointed out the need to develop recovery plans to reduce the onset of mental illness and maximize the chance for psychological growth among HCWs [32,33].

Although a worldwide PPE shortage did occur during the present situation, almost half (48\%) of the current sample reported inadequate access to it. Furthermore, that perception was unequal among professionals from different regions. Professionals working in Cataluña and the RRs perceived that they had access to enough PPE always or most of the time, but in Madrid, the general perception was of a lack of adequate equipment for self-protection. Despite the benefits of decentralized health care management, some aspects should be regulated by the central government to prevent inequities of access to specific materials such as PPE [34,35]. The decentralized health care system in Spain has already been the subject of different 
analyses, and the pandemic has revitalized those debates in the scientific and political communities; similar analyses have been conducted in other countries with decentralized health care systems [36].

Regarding social and work-related variables, it should be highlighted that professionals in Madrid had less ICU work experience than HCWs in other regions. Patients admitted to the ICU during the pandemic had elevated care needs, required highly complex procedures and assistance, and would have benefited from the care of highly trained professionals. Several scientific societies have made statements highlighting the importance of being able to access professionals able to adequately work in critical care and effectively manage COVID-19 patients, emphasizing the need to train new specialists to be prepared for future outbreaks [37-39]. Specifically in Spain, registered nurses don't have a specialty in critical care that is regulated by the Health Ministry, despite demand for one over many years by professionals working in the field, professional societies, and professional colleges. The current pandemic could be an opportunity to finally fully develop that specialty [37]. Moreover, the need to create multidisciplinary teams that can attend to critical care patients in times of crisis is a fact, and the prominent role of anesthesiologists during this pandemic has reinforced their supporting role in critical care facilities [40,41]. On the other hand, it's interesting to note that most of the HCWs in our sample perceived that their overall workload had been greater than usual, despite the fact that the patient to professional ratio had not increased. Although we don't have enough information to determine why that discrepancy occurred, we suspect that it reflects the high complexity and care needs of COVID-19 patients and the high proportion of professionals without much experience in managing critical care patients who were asked to work in the ICU during this moment [42]. Further research is necessary to analyze that finding in more depth.

Most of our respondents reported having suffered from some COVID-19-related symptoms during the pandemic. The most frequently reported were unspecific and could be associated with other situations, such as headaches, which were reported by almost $75 \%$ of our professional respondents. Headaches could be associated with other situations, such as the high workload, elevated number of work shifts, or the stress derived from taking care of COVID-19 patients. In fact, Ong et al. [43] found that up to $81 \%$ of professionals reported suffering headaches or exacerbations of their usual headaches, which could also be related to the continuous use of PPE. Some of the symptoms reported could have derived from being in a lockdown, which was an extra stressor for HCWs. Several studies have highlighted the role of the lockdown in the emergence of unspecific physical symptoms, as well as the appearance of anxiety and stress among the general population; therefore, it cannot be ruled out that something similar could have happened among ICU workers [44-46].

Symptoms specific to COVID-19, such as shortness of breath or fever, appeared at a lower, but still significant, frequency (from $8.9 \%$ to $42.2 \%$ ) in the current sample of ICU workers. These results are similar to those found by Cao et al. [47], who reported that practically all the professionals in their sample suffered from mild body discomfort, including tiredness; sore throat; cough; neck, shoulder and back pain; nausea; and even skin manifestations, although none of those participants were infected by the coronavirus [48].

This study has some limitations, the most important of which could be the non-probabilistic sample selection, which might have caused the overrepresentation of certain regions (mainly Madrid and Cataluña, which were more affected by the pandemic than other areas) and work categories. This is a correlational study and thus cannot establish causality among the results. Furthermore, we could not analyze the relationships between certain variables, such as working conditions and anxiety. However, despite those limitations, this is the first work to assess the effects of work-related variables on HCWs in the Spanish health care system during the COVID-19 pandemic; it provides particularly interesting information about the effects that worries about contagion and anxiety had on respondents.

Due to the magnitude and characteristics of the COVID-19 pandemic, ICU staff have been severely affected both physically and psychologically. In this study, high levels of anxiety were found among HCWs who cared directly for COVID-19 patients. The long-term psychological consequences of those alterations still need to be assessed. As different authors have highlighted, programs to mitigate anxiety among HCWs should be integrated into hospital policies to prepare for future pandemics.

\section{CONFLICT OF INTEREST}

No potential conflict of interest relevant to this article was reported.

\section{ORCID}

Fernando J. García-Hedrera

https://orcid.org/0000-0001-5539-5773 
Fernanda Gil-Almagro

https://orcid.org/0000-0002-1079-281X

F. Javier Carmona-Monge

https://orcid.org/0000-0003-3431-238X

Cecilia Peñacoba-Puente

https://orcid.org/0000-0001-6307-5921

Patricia Catalá-Mesón

https://orcid.org/0000-0003-4989-9099

Lilian Velasco-Furlong

https://orcid.org/0000-0002-6787-324X

\section{AUTHOR CONTRIBUTIONS}

Conceptualization: FGA, FJCM. Data curation: FJGH, CPP. Formal analysis: CPP, PCM, LVF. Methodology: FGA. Project administration: FJCM. Visualization: FJGH. Writing-original draft: FGA, FJGH. Writing-review \& editing: PCM, LVF.

\section{REFERENCES}

1. Chen N, Zhou M, Dong X, Qu J, Gong F, Han Y, et al. Epidemiological and clinical characteristics of 99 cases of 2019 novel coronavirus pneumonia in Wuhan, China: a descriptive study. Lancet 2020;395:507-13.

2. The Lancet. Emerging understandings of 2019-nCoV. Lancet 2020;395:311.

3. World Health Organization. Novel Coronavirus (2019-nCoV) technical guidance [Internet]. Geneva: World Health Organization; 2020 [cited 2020 Aug 10]. Available from: https://www. who.int/emergencies/diseases/novel-coronavirus-2019/technical-guidance.

4. Vestergaard LS, Nielsen J, Richter L, Schmid D, Bustos N, Braeye $\mathrm{T}$, et al. Excess all-cause mortality during the COVID-19 pandemic in Europe: preliminary pooled estimates from the EuroMOMO network, March to April 2020. Euro Surveill 2020; 25:2001214.

5. James N, Menzies M, Radchenko P. COVID-19 second wave mortality in Europe and the United States. Chaos 2021;31:031105.

6. Legido-Quigley H, Mateos-García JT, Campos VR, Gea-Sánchez M, Muntaner C, McKee M. The resilience of the Spanish health system against the COVID-19 pandemic. Lancet Public Health 2020;5:e251-2.

7. Parrado S, Galli D. Intergovernmental veto points in crisis management: Italy and Spain facing the COVID-19 pandemic. Int Rev Adm Sci 2021 Jan 17 [Epub]. https://doi.org/10.1177/002 0852320985925.

8. Ministerio de Sanidad. Enfermedad por nuevo coronavirus,
COVID-19. Situación actual [Internet]. Madrid: Ministerio de Sanidad; 2020 [cited 2020 Aug 10]. Available from: https:// www.mscbs.gob.es/profesionales/saludPublica/ccayes/alertasActual/nCov-China/situacionActual.htm.

9. Ripp J, Peccoralo L, Charney D. Attending to the emotional well-being of the health care workforce in a New York City health system during the COVID-19 pandemic. Acad Med 2020;95:1136-9.

10. Lintern S. Coronavirus: Italian doctors warn protective equipment vital to prevent healthcare system collapse. London: Independent; 2020.

11. Sevillano EG. La falta de mascarillas y respiradores pone en tensión a los hospitales españoles [Internet]. Sociedad: El País; 2020 [cited 2021 Jul 30]. Available from: https://elpais. com/sociedad/2020-03-12/la-falta-de-mascarillas-y-respiradores-pone-en-tension-a-los-hospitales-espanoles.html.

12. Lai J, Ma S, Wang Y, Cai Z, Hu J, Wei N, et al. Factors associated with mental health outcomes among health care workers exposed to coronavirus disease 2019. JAMA Netw Open 2020;3: e203976.

13. Maunder R, Hunter J, Vincent L, Bennett J, Peladeau N, Leszcz $\mathrm{M}$, et al. The immediate psychological and occupational impact of the 2003 SARS outbreak in a teaching hospital. CMAJ 2003;168:1245-51.

14. Dai Y, Hu G, Xiong H, Qiu H, Yuan X. Psychological impact of the coronavirus disease 2019 (COVID-19) outbreak on healthcare workers in China. MedRxiv 20030874 [Preprint]. 2020 [cited 2021 Jan 1]. Available from: https://doi.org/10.1101/20 20.03.03.20030874.

15. Dubey S, Biswas P, Ghosh R, Chatterjee S, Dubey MJ, Chatterjee S, et al. Psychosocial impact of COVID-19. Diabetes Metab Syndr 2020;14:779-88.

16. Lee SM, Kang WS, Cho AR, Kim T, Park JK. Psychological impact of the 2015 MERS outbreak on hospital workers and quarantined hemodialysis patients. Compr Psychiatry 2018;87: 123-7.

17. Kim HC, Yoo SY, Lee BH, Lee SH, Shin HS. Psychiatric findings in suspected and confirmed middle east respiratory syndrome patients quarantined in hospital: a retrospective chart analysis. Psychiatry Investig 2018;15:355-60.

18. Wu KK, Chan SK, Ma TM. Posttraumatic stress after SARS. Emerg Infect Dis 2005;11:1297-300.

19. Wang C, Pan R, Wan X, Tan Y, Xu L, Ho CS, et al. Immediate psychological responses and associated factors during the initial stage of the 2019 coronavirus disease (COVID-19) epidemic among the general population in China. Int J Environ Res Public Health 2020;17:1729. 
20. Stokes EK, Zambrano LD, Anderson KN, Marder EP, Raz KM, El Burai Felix S, et al. Coronavirus disease 2019 case surveillance: United States, January 22-May 30, 2020. MMWR Morb Mortal Wkly Rep 2020;69:759-65.

21. Spitzer RL, Kroenke K, Williams JB, Löwe B. A brief measure for assessing generalized anxiety disorder: the GAD-7. Arch Intern Med 2006;166:1092-7.

22. Muñoz-Navarro R, Cano-Vindel A, Moriana JA, Medrano LA, Ruiz-Rodríguez P, Agüero-Gento L, et al. Screening for generalized anxiety disorder in Spanish primary care centers with the GAD-7. Psychiatry Res 2017;256:312-7.

23. Pappa S, Ntella V, Giannakas T, Giannakoulis VG, Papoutsi E, Katsaounou P. Prevalence of depression, anxiety, and insomnia among healthcare workers during the COVID-19 pandemic: a systematic review and meta-analysis. Brain Behav Immun 2020;88:901-7.

24. Huang L, Lei W, Xu F, Liu H, Yu L. Emotional responses and coping strategies in nurses and nursing students during Covid-19 outbreak: a comparative study. PLoS One 2020;15:e237303.

25. Liu N, Zhang F, Wei C, Jia Y, Shang Z, Sun L, et al. Prevalence and predictors of PTSS during COVID-19 outbreak in China hardest-hit areas: gender differences matter. Psychiatry Res 2020;287:112921.

26. Zhang WR, Wang K, Yin L, Zhao WF, Xue Q, Peng M, et al. Mental health and psychosocial problems of medical health workers during the COVID-19 epidemic in China. Psychother Psychosom 2020;89:242-50.

27. Rossi R, Socci V, Pacitti F, Di Lorenzo G, Di Marco A, Siracusano A, et al. Mental health outcomes among frontline and second-line health care workers during the coronavirus disease 2019 (COVID-19) pandemic in Italy. JAMA Netw Open 2020; 3:e2010185.

28. Shechter A, Diaz F, Moise N, Anstey DE, Ye S, Agarwal S, et al. Psychological distress, coping behaviors, and preferences for support among New York healthcare workers during the COVID-19 pandemic. Gen Hosp Psychiatry 2020;66:1-8.

29. González-Sanguino C, Ausín B, Castellanos MÁ, Saiz J, LópezGómez A, Ugidos C, et al. Mental health consequences during the initial stage of the 2020 coronavirus pandemic (COVID-19) in Spain. Brain Behav Immun 2020;87:172-6.

30. Badahdah A, Khamis F, Al Mahyijari N, Al Balushi M, Al Hatmi H, Al Salmi I, et al. The mental health of health care workers in Oman during the COVID-19 pandemic. Int J Soc Psychiatry 2021;67:90-5.

31. Feinstein RE, Kotara S, Jones B, Shanor D, Nemeroff CB. A health care workers mental health crisis line in the age of $\mathrm{CO}$ VID-19. Depress Anxiety 2020;37:822-6.
32. Greenberg N, Brooks SK, Wessely S, Tracy DK. How might the NHS protect the mental health of health-care workers after the COVID-19 crisis? Lancet Psychiatry 2020;7:733-4.

33. Canady VA. MH leaders, insurers unite on COVID-19 resource toolkit. Ment Health Wkly 2020;30:3-5.

34. Hortal-Carmona J, Padilla-Bernáldez J, Melguizo-Jiménez M, Ausín T, Cruz-Piqueras M, López de la Vieja MT, et al. Efficiency is not enough. Ethical analysis and recommendations for the allocation of scarce resources in a pandemic situation. Gac Sanit 2021 Jan 25 [Epub]. https://doi.org/10.1016/j.gaceta.2020.07.006.

35. Campos MS, Fernández-Montes A, Gavilan JM, Velasco F. Public resource usage in health systems: a data envelopment analysis of the efficiency of health systems of autonomous communities in Spain. Public Health 2016;138:33-40.

36. Bello-Gomez RA, Sanabria-Pulido P. The costs and benefits of duality: Colombia's decentralization and the response to the COVID-19 pandemic. Rev Adm Publica 2021;55:165-79.

37. Raurell-Torredà M, Martínez-Estalella G, Frade-Mera MJ, Carrasco Rodríguez-Rey LF, Romero de San Pío E. Reflections arising from the COVID-19 pandemic. Enferm Intensiva (Engl Ed) 2020;31:90-3.

38. Raurell-Torredà M. Management of ICU nursing teams during the COVID-19 pandemic. Enferm Intensiva (Engl Ed) 2020; 31:49-51.

39. Rascado Sedes P, Ballesteros Sanz MÁ, Bodí Saera MA, Carrasco RodríguezRey LF, Castellanos Ortega Á, Catalán González $\mathrm{M}$, et al. Plan de contingencia para los servicios de medicina intensiva frente a la pandemia COVID-19. Med Intensiva 2020; 44:363-70

40. Yang M, Dong H, Lu Z. Role of anaesthesiologists during the COVID-19 outbreak in China. Br J Anaesth 2020;124:666-9.

41. Ferrando C, Colomina MJ, Errando CL, Llau JV. Anesthesiology and the anesthesiologists at COVID-19. Rev Esp Anestesiol Reanim (Engl Ed) 2020;67:289-91.

42. Nayna Schwerdtle P, Connell CJ, Lee S, Plummer V, Russo PL, Endacott R, et al. Nurse expertise: a critical resource in the COVID-19 pandemic response. Ann Glob Health 2020;86:49.

43. Ong JJ, Bharatendu C, Goh Y, Tang JZ, Sooi KW, Tan YL, et al. Headaches associated with personal protective equipment: a cross-sectional study among frontline healthcare workers during COVID-19. Headache 2020;60:864-77.

44. Gómez-Salgado J, Andrés-Villas M, Domínguez-Salas S, DíazMilanés D, Ruiz-Frutos C. Related health factors of psychological distress during the COVID-19 pandemic in Spain. Int J Environ Res Public Health 2020;17:3947.

45. Mengin A, Allé MC, Rolling J, Ligier F, Schroder C, Lalanne L, 
et al. Psychopathological consequences of confinement. Encephale 2020;46:S43-52.

46. Ammar A, Brach M, Trabelsi K, Chtourou H, Boukhris O, Masmoudi L, et al. Effects of COVID-19 home confinement on eating behaviour and physical activity: results of the ECLBCOVID19 international online survey. Nutrients 2020;12:1583.

47. Cao J, Wei J, Zhu H, Duan Y, Geng W, Hong X, et al. A study of basic needs and psychological wellbeing of medical workers in the fever clinic of a tertiary general hospital in Beijing during the COVID-19 outbreak. Psychother Psychosom 2020;89: 252-4.

48. Chew NW, Lee GK, Tan BY, Jing M, Goh Y, Ngiam NJ, et al. A multinational, multicentre study on the psychological outcomes and associated physical symptoms amongst healthcare workers during COVID-19 outbreak. Brain Behav Immun 2020; 88:559-65. 